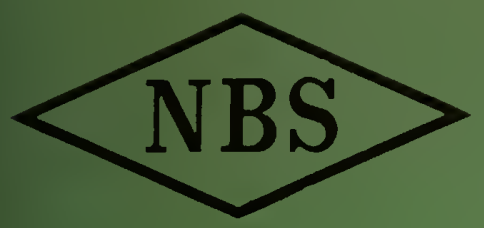

Eechnical Note

$\eta_{0 .} 148$

Boulder Laboratories

\title{
A WIRE EXPLODER FOR GENERATING CYLINDRICAL SHOCK WAVES IN A CONTROLLED ATMOSPHERE
}

BY D. L. JONES AND K. B. EARNSHAW 


\section{THE NATIONAL BUREAU OF STANDARDS}

\section{Functions and Activities}

The functions of the National Bureau of Standards are set forth in the Act of Congress, March 3, 1901, as amended by Congress in Public Law 619, 1950. These include the development and maintenance of the national standards of measurement and the provision of means and methods for making measurements consistent with these standards; the determination of physical constants and properties of materials; the development of methods and instruments for testing materials, devices, and structures; advisory services to government agencies on scientific and technical problems; invention and development of devices to serve special needs of the Government; and the development of standard practices, codes, and specifications. The work includes basic and applied research, development, engineering, instrumentation, testing, evaluation, calibration services, and various consultation and information services. Research projects are also performed for other government agencies when the work relates to and supplements the basic program of the Bureau or when the Bureau's unique competence is required. The scope of activities is suggested by the listing of divisions and sections on the inside of the back cover.

\section{Publications}

The results of the Bureau's research are published either in the Bureau's own series of publications or in the journals of professional and scientific societies. The Bureau itself publishes three periodicals available from the Government Printing Office: The Journal of Research, published in four separate sections, presents complete scientific and technical papers; the Technical News Bulletin presents summary and preliminary reports on work in progress; and Basic Radio Propagation Predictions provides data for determining the best frequencies to use for radio communications thro ugho ut the world. There are also five series of nonperiodical publications: Monographs, Applied Mathematics Series, Handbooks, Miscellaneous Publications, and Technical Notes.

A complete listing of the Bureau's publications can be found in National Bureau of Standards Circular 460, Publications of the National Bureau of Standards, 1901 to June 1947 (\$1.25), and the Supplement to National Bureau of Standards Circular 460, July 1947 to June 1957 (\$1.50), and Miscellaneous Publication 240, July 1957 to June 1960 (Includes Titles of Papers Published in Outside Journals 1950 to 1959) (\$2.25); available from the Superintendent of Documents, Government Printing Office, Washington 25, D. C. 


\section{NATIONAL BUREAU OF STANDARDS Eechnical Mote}

148

May 1962

A WIRE EXPIODER FOR GENERATING CYLINDRICAL SHOCK WAVES

IN A CONTROLIED ATMOSPHERE

hy

D. L. Jones and K. B. Earnshaw

NBS Technical Notes are designed to supplement the Bureau's regular publications program. They provide a means for making available scientific data that are of transient or limited interest. Technical Notes may be listed or referred to in the open literature. They are for sale by the Office of Technical Services, U. S. Department of Commerce, Washington 25, D. C.

DISTRIBUTED BY

\section{UNITED STATES DEPARTMENT OF COMMERCE} OFFICE OF TECHNICAL SERVICES

WASHINGTON 25, D. C.

Price $\$ .50$ 

February 16, 1962

A WIRE EXPLODER FOR GENERATING CYLINDRICAL SHOCK WAVES IN A CONTROLUED ATMOSPHERE

$$
\text { by }
$$

D. L. Jones and K. B. Earnshaw

National Bureau of Standards, Boulder, Colorado

\section{ABSTRACT}

A design for a rugged exploding wire device is given. This device permits the study of strong cylindrical shock waves in controlled atmospheres using optical and microwave techniques. Adequate detail and pictures are given to allow construction of the device. 



\title{
A WIRE EXPLODER FOR GENFRATING CYLINDRICAL SHOCK WAVES IN A CONTROLLED ATMOSPHERE
}

\author{
by
}

D. L. Jones and K. B. Earnshaw

National Bureau of Standards, Boulder, Colorado

Very little information on exploding wire devices is reported in the literature. Normally, exploding wire studies are made in air and it is the exploding wire itself that is of interest. ${ }^{1,2}$ For these studies, the device for exploding the wire may easily be made to have the necessary low inductanceelectrical connections. In the few instances where the shock waves from the explosion have been investigated ${ }^{3}$, 4 relatively low energy capacitor banks ( 150 joules) were used. However, in order to study strong shock waves in a controlled atmosphere using a capacitor bank of 1500 joules or more a rugged blast chamber is required. For optical or microwave observations, the chamber must also be made of a transparent material.

The purpose of this paper is to report a ruggedly designed exploding wire device which can be used for optical and microwave investigations of strong cylindrical shock waves. The particular advantages of this device are: 1) the electrical connections are designed to have a minimum inductance; 2) the pressure and type of gas are controllable; 3) the device is simple to assemble, and cleaning of the chamber is quite easy; 4) the wire is held in place by gravity; and 5) the electrodes for the current return path are removed far enough from the wire axis to minimize mechanical interference with the expanding shock wave. 

The assembled wire exploder is shown in Figure 1. The dark vertical line in the center is the wire which passes through the IId and the cross arm and makes contact with the bottom electrode. An exploded view of the device is shown in Fig. 2. Lids A and D are made of plexiglass one inch thick with a diameter of $12 \frac{1}{4}$ Inches. Plexiglass cylinder $\mathrm{C}$ is 3 inches long, $\frac{1}{4}$ inch thick, and has an $11 \frac{1}{2}$ inch I.D. Vacuum joints between the lids and the cylinder are obtained by the rubber "O" rings which are visible in Fig. 2 .

The current return path (cross arm B) is made from brass bar stock which is covered with a sheath of rubber insulation to avoid arcing. The cross arm is bolted to plate $E$ through the bottom lid D, securing lid D to the plate. An "O" ring seal between cross arm $\mathrm{B}$ and lid $\mathrm{D}$ provides a vacuum seal. Plate $\mathrm{E}$ is fastened to the bottom member $G$ which is attached to ground. Both plate $E$ and member $G$ are made of $\frac{1}{2}$-inch brass.

The cylindrical insulator $J$, which encloses a spark gap switch, is made of teflon with an outer diameter 2.88 inches and inner diameter of 2.41 inches. This insulator fits into the machined groove in lid D, through the holes in parts $G$ and $E$. The top spark gap electrode I is of brass with an outer diameter of 2.40 inches. It fits into insulator $J$ with the top part $(H)$ fitting into lid D. The upper $3 / 8$ inch of electrode I (part $H$ ) consists of a $\frac{1}{4}$-inch diameter rod covered with a one inch diameter teflon cylinder. The " $O$ " $r$ ing in the teflon cylinder provides a vacuum seal for the electrode. The bottom spark gap (electrode K) which is normally attached directly to the capacitor, is made of 2.40 inch outer diameter aluminum. It belongs inside insulator $J$ near the bottom. 

Triggering is obtained by means of a high voltage pulse brought to the top spark gap electrode through a $\frac{1}{2}$-inch hole in cylinder F. A length of $\frac{1}{4}$-inch $I . D$. vacuum tubing outside the trigger cable insulates the cable from cylinder $F$. The trigger cable comes out flush with the center of the top electrode of the spark gap.

Fittings for gas inlet and vacuum taps may be placed at any convenient point in either lids $A$ and $D$ or cylinder $C$.

Tests with this device show it to be capable of maintaining a vacuum of 50 microns with a standard fore pump. Mass spectrometer analyses of argon gas samples taken under normal operating conditions at $10 \mathrm{~cm}$. $\mathrm{Hg}$. indlcate that the gas purity is maintained to better than one part in $10^{4}$, or about the standard guaranteed for bottled gases. System inductance depends on the wire size, the pressure and the voltage, but a typical value (without capacitors) is $48 \times 10^{-9}$ Henry, including switch inductance. Working voltages have ranged $3 \mathrm{KV}$ to $20 \mathrm{KV}$ while maximum current at $20 \mathrm{KV}$ is about 150,000 amperes.

This exploding wire device has been used to generate type III blasts ${ }^{5}$ at pressures ranging from atmospheric to five centimeters of mercury. Shock front velocity and distance measurements obtained by the microwave Doppler Method ${ }^{6}$ show that detectable shocks travel out as far as seven or eight centimeters from the wire axis. In fact, measurements of the velocity are made until the electron density in the front falls below the $10^{13} \mathrm{~cm}^{-3}$ which is required to reflect the microwaves. Using the measurements the similarity theory for strong cylindrical blast waves ${ }^{7}$ has been verified to velocities as low as Mach number 3 in air. 

REFERENCES

1) W. G. Chace, "A Bibliography of the Electrically Exploded Wire Phenomena," GRD-TM-57-5, Air Force Cambridge Research Center; Bedford, Massachusetts (Nov. 1956).

2) W. G. Chace, H. K. Moore, Exploding Wires, Plenum Press Inc., New York, (1959).

3) F. D. Bennett, "Flow Fields Produced by Exploding Wires" in Reference 2, p. 211.

4) K. Oshima, "Experiments on the Cylindrical Blast Waves" J. Phys. Soc. Japan, 12, 1421, (1957).

5) W. G. Chace, M. A. Levine, "Classification of Wire Explosions," J. Appl. Phys., 31, 1298, (1960).

6) D. L. Jones, R. M. Gallet, "Microwave Doppler Measurements of the Ionization Front in Cylindrical Shock Waves from Exploding Wires," Exploding Wires, Vol. II, Plenum Press Inc., New York, in publication.

7) S. C. Iin, "Cylindrical Shock Waves Produced by Instantaneous Energy Release," J. Appl. Phys., 25, 54, (1954). 



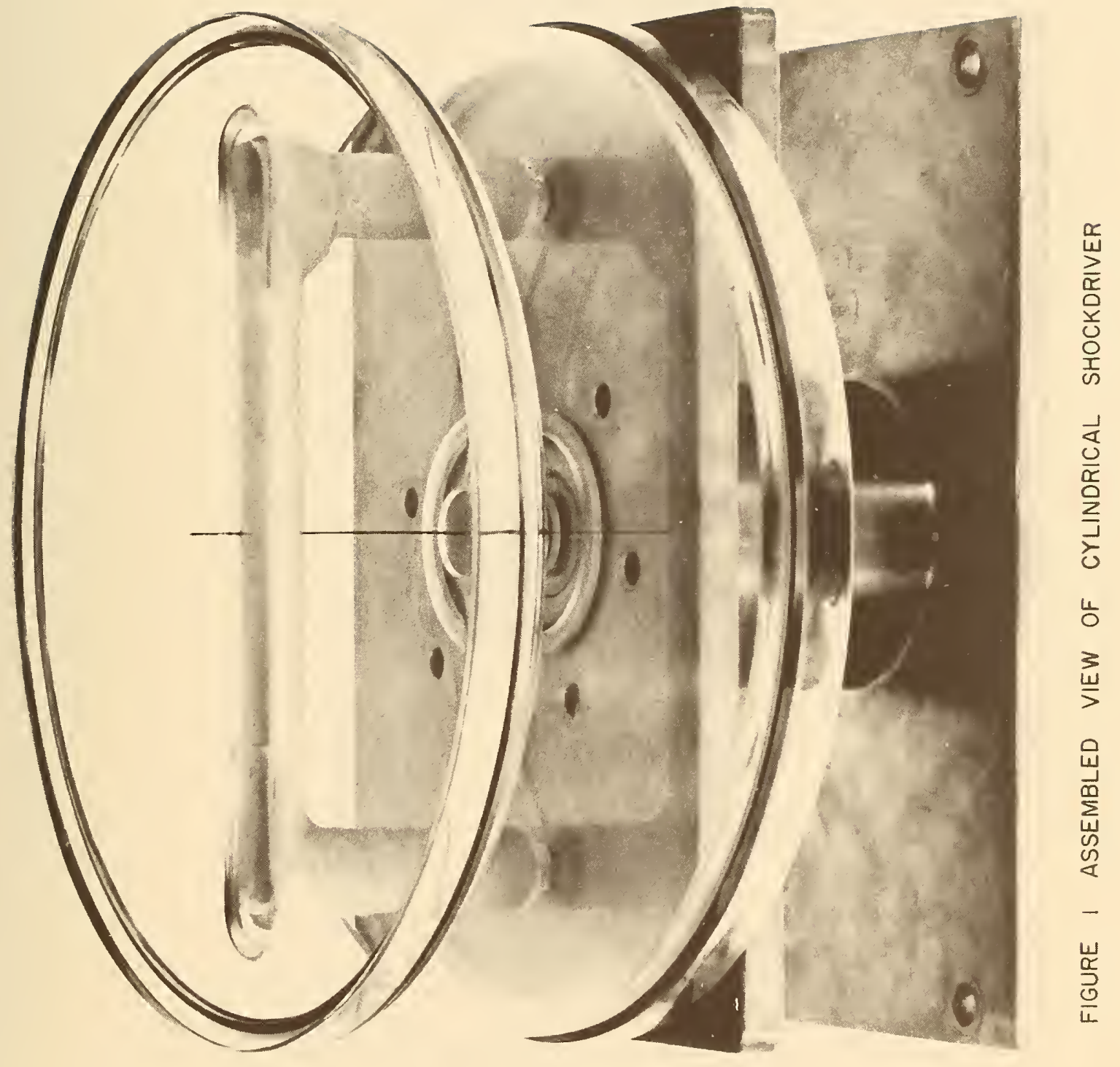





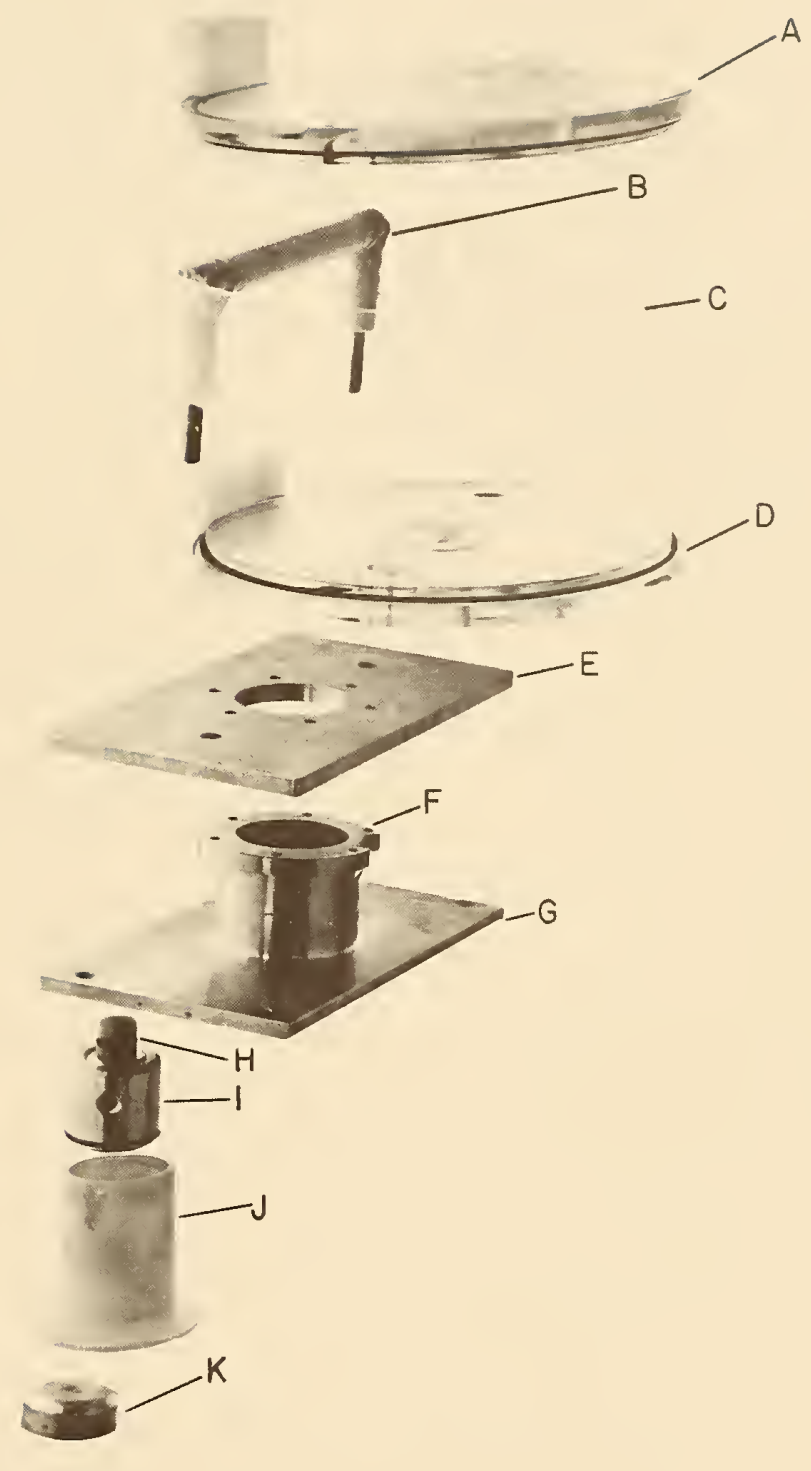

FIGURE 2. EXPLODED VIEW OF CYLINDRICAL SHOCKDRIVER 



\section{U. S. DEPARTMENT OF COMMERCE}

Luther H. Hodges, Secretary

NATIONAL RUREAU OF STANDARDS

A. V. Astin, Director

\section{THE NATIONAL BUREAU OF STANDARDS}

The scope of activities of the National Bureau of Standards at its major laboratories in Washington, U.C., and Boulder, Colorado, is suggested in the following listing of the divisions and sections engaged in technical work. ln general, each section carries out specialized research, development, and engineering in the field indicated by its title. A brief description of the activities, and of the resultant publications, appears on the inside of the front cover.

\section{WASHLNGTON, D.C.}

Electricity. Resistance and Reactance. Electrochemistry. Electrical Instruments. Magnetic Measurements. Dielectrics. High Voltage.

Metrology. Photometry and Colorimetry. Refractometry. Photographic Research. Length. Engineering Metrology. Mass and Scale. Volumetry and Densimetry.

lleat. Temperature Physics. Heat Measurements. Cryogenic Physics. Equation of State. Statistical Physics. Radiation Physics. X-ray. Radioactivity. Radiation Theory. High Energy Radiation. Radiological Equipment. Nucleonic Instrumentation. Neutron Physics.

Analytical and Inorganic Chemistry. Pure Substances. Spectrochemistry. Solution Chemistry. Standard Reference Materials. Applied Analytical Research.

Mechanics. Sound. Pressure and Vacuum. Fluid Mechanics. Engineering Mechanics. Rheology. Combustion Controls.

Organic and Fibrous Materials. Rubber. Textiles. Paper. Leather. Testing and Specifications. Polymer Structure. Plastics. Dental Research.

Metallurgy. Thermal Metallurgy. Chemical Metallurgy. Mechanical Metallurgy. Corrosion. Metal Physics. Electrolysis and Metal Deposition.

Mineral Products. Engineering Ceramics. Glass. Refractories. Enameled Metals. Crystal Growth. Physical Properties. Constitution and Microstructure.

Building Research. Structural Engineering. Fire Research. Mechanical Systems. Organic Building Materials. Codes and Safety Standards. Heat Transfer. Inorganic Building Materials.

Applied Mathematics. Numerical Analysis. Computation. Statistical Engineering. Mathematical Physics. Operations Research.

Data Processing Systems. Components and Techniques. Computer Technology. Measurements Automation. Engineering Applications. Systems Analysis.

Atomic Physics. Spectroscopy. Infrared Spectroscopy. Solid State Physics. Electron Physics. Atomic Physics. Instrumentation. Engineering Electronics. Electron Devices. Electronic Instrumentation. Mechanical Instruments. Basic Instrumentation.

Physical Chemistry. Thermochemistry. Surface Chemistry. Organic Chemistry. Molecular Spectroscopy. Molecular Kinetics. Mass Spectrometry.

Office of Weights and Measures.

\section{BOULDER, COLO.}

Cryogenic Engineering. Cryogenic Equipment. Cryogenic Processes. Properties of Materials. Cryogenic Technical Services.

Ionosphere Research and Propagation. Low Frequency and Very Low Frequencv Research. Ionosphere Research. Prediction Services. Sun-Earth Relationships. Field Engineering. Radio Warning Services. Vertical Soundings Research.

Radıo Propagation Engineering. Data Reduction Instrumentation. Radio Noise. Tropospheric Measurements. Tropospheric Analysis. Propagation-Terrain Effects. Radio-Meteorology. Lower Atmosphere Physics.

Radio Staniards. High Frequency Electrical Standards. Radio Broadcast Service. Radio and Microwave Materials. Atomic Frequency and Time Interval Standards. Electronic Calibration Center. Millimeter-Wave Research. Microwave Circuit Standards.

Radio Systems. Applied Electromagnetic Theory. High Frequency and Very High Frequency Research. Modulation Research. Antenna Research. Navigation Systems.

Upper Atmosphere and Space Physics. Upper Atmosphere and Plasma Physics. Ionosphere and Exosphere Scatter. Airglow and Aurora. Ionospheric Radio Astronomy. 
No. 149 cancelled 


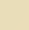

